\title{
Experimental Research of a Particular Free Power Turbine Application
}

\author{
Razvan Marius CATANA*, Gabriel DEDIU, Cornel Mihai TARABIC
}

\begin{abstract}
The paper presents an experimental research and a particular operation mode of testing, for an industrial application. The application refers to one stage axial gas free power turbine, run by the gases provided from two gas generators of TV2-117A turboshaft engines. By running the free power turbine is analysed the starting and idle mode of TV2-117A modified engines and of free turbine. After the analysing, the major interest is how to be operated on higher modes than idle. To modify the TV2$117 \mathrm{~A}$ turboshaft engine into an only gas generator, the free power assembly module was removed from the engine and the gas flow was delivered into one turbine. Also the conversion of TV2-117 turboshaft engine into a gas generator involves a modification into the engine fuel control. The gases from both the engines flow to an only one gas turbine and the turbine produces shaft power. The testing of the free power turbine is performed on the test bench by using a dynamometer and an operating system. For both, we use an acquisition system and a programmable controller using an operating sequence. The operating sequence is based on parameters and commands, used to control and monitor the engine. The free power turbine is designed to run a natural gas compressor for industrial application and at sea level conditions it develops a power of $2600 \mathrm{~kW}$ at a speed of $15000 \mathrm{rpm}$. The contribution of this paper is the study of behaviour of every engine and the free power turbine at start-up and for the idle mode.
\end{abstract}

Keywords: aero derivate; free power turbine; gas flow; starting; turboshaft

\section{INTRODUCTION}

In present, gas turbines are one of the most used power generating technologies. Generally most of the gas turbine engines, after the end of the operating resource, are used in industrial applications as cogeneration plants or horizontal applications [1, 2]. There are a lot of applications [3, 4], that include aviation engines, and a large interest in how to transform an aviation engine into an aero derivative engine or how to be implemented into horizontal applications, to achieve a power plant installation more efficiently. Usually turboshaft and turboprop engines are the most available for transformation from an aviation engine into an aero derivative engine or into industrial engine for horizontal applications; because the turboshaft engine produces shaft power, it is accessible to connect the engine shaft with different electrical or mechanical assemblies as are electrical generators, marine propellers or gas compressors $[5,6]$.

Most of the larger aero engine manufacturers as GE, Prat \& Whitney, Rolls-Royce manufacture also aero derivative engine or industrial engines that are used by the power plant manufacturers as GE Power [6], Systems, Siemens [7], Turbine Technics [8], Mitsubishi Heavy Industries [9], MTU [10], but are also manufacturers who produce only industrial engines as MAN Turbo [11]. In some particular application, an aviation engine, which is close to the end of run resource, to be used into an industrial application is required to be totally repaired to extend to operating resource and to be transformed into a new functionally working configuration. In some particular cases of power generation or marine applications, smaller than $5 \mathrm{MW}$, most of the used aero derivative engines are from PW100 and PW150 turboprop family [12], Ivchenko Progress as AI-20 turboprop family [13] or Klimov TV3117 turboshaft family [14]. This paper presents a horizontal application of a free gas power turbine, using two modified TV2-117A turboshaft engines [15], tested in a test bench, and which was designed to run a natural gas compressor.

\section{DESCRIPTION OF APPLICATION}

The TV2-117A [15], Fig. 1, is a turboshaft engine with a free-turbine composed of two spools, the spool of the gas generator or core engine and the spool of the free power turbine. The gas generator consists of nine axial compressor stages, of which four stator vane stages are with variable stager angle, an annular combustion chamber and two stage axial turbines. The free power turbine is also an axial turbine, consisting of two stages and is mechanically connected with the helicopter main gear through the free power turbine shaft.

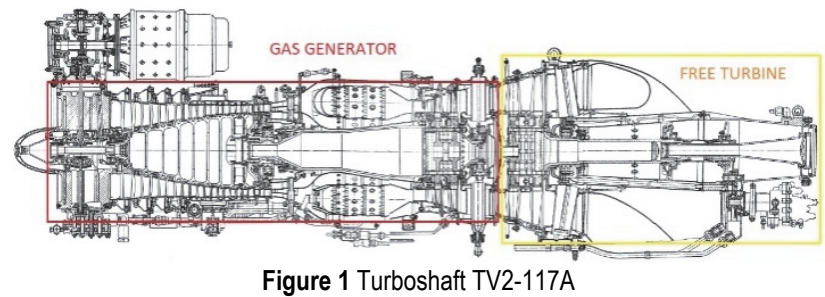

The paper presents a particular study application of a free gas turbine using two modified TV2-117A turboshaft engines. The two TV2-117A turboshaft engines are in the same installing configuration as on helicopter, but on a different configuration of the exhaust gases flow.

In the flight configuration, every engine has its own exhaust nozzle and the gases flows, as gfl and gf2, from every engine are exhausted into the atmosphere. In this particular application, on test configuration, the gas flows from the engines are mixed and flow into one turbine, which produces power by expansion of the gases, and then the gases are exhausted into one outlet nozzle, which is a part of the new free power turbine module.

On helicopter configuration [15], Fig. 2 and Fig. 3, both engines transfer the power and the speed of the free power turbine into one main gear which transfers the power to the main rotor blade. At sea level conditions, on takeoff, the main rotor blade receives from each engine $\approx 1105$ $\mathrm{kW}$ power at $12000 \mathrm{rpm}$ free turbine speed. 


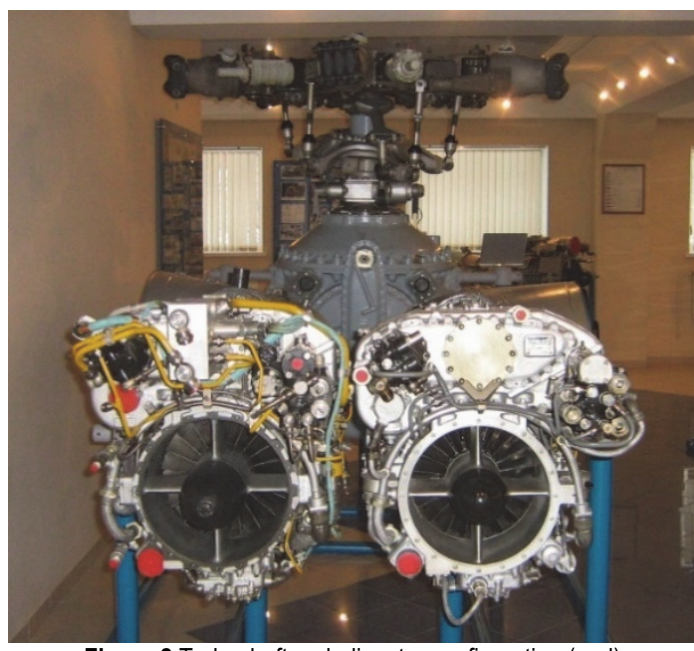

Figure 2 Turboshaft on helicopter configuration (real)

gf

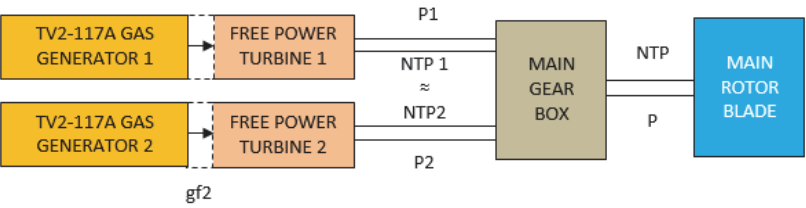

Figure 3 Turboshaft on helicopter configuration (real)

On helicopter configuration, in the idle mode [15], the engine develops maximum power of around $\mathrm{P} \approx 60 \mathrm{~kW}$, at $\mathrm{NTP} \approx 45 \pm 10 \%$ free power turbine speed and gas generator speed of around $\mathrm{NGG} \approx 65 \pm 1 \%$. At take-off the rotor of the gas generator works at a maximum speed of $\mathrm{NGG} \approx 21200 \mathrm{rpm}$, delivers an air flow rate of around $\mathrm{AF}$ $\approx 7.5 \mathrm{~kg} / \mathrm{s}$, and makes an overall pressure ratio $\approx 6.5: 1$, at the maximum free power turbine speed of NTP $\approx 12000$ $\mathrm{rpm}$. In this case, the engine must have the same running mode to transfer the same speed of free turbines to the main gear. To avoid the problems of the free power turbine speed, to be held into the same values, every engine is equipped with a hydraulic unit component which, in connection with the main fuel pump, has the role to maintain almost the same core speed of engines.

On the test bench, for this particular application, to test the free power turbine are used two modified TV2-117A turboshaft engines. The engines are transformed only into a gas generator, or core engine, by removing the free power assembly module from the engine.

In this case, Fig. 4, the gas flows from every engine are mixed into one gasflow that is delivered through a nozzle vane to one single turbine rotor. Because it is a free turbine, the connection between the gas generators and the turbine is only gasodynamic, and there is not a mechanical connection.

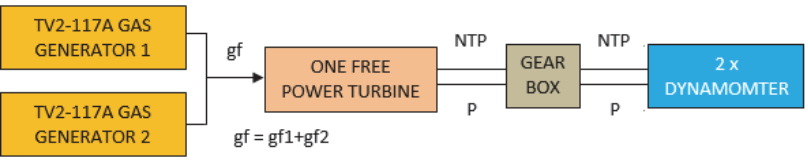

Figure 4 Free power turbine application configuration (scheme)

Fig. 5, Fig. 6 and Fig. 7 represent the gas generators in testing configuration.

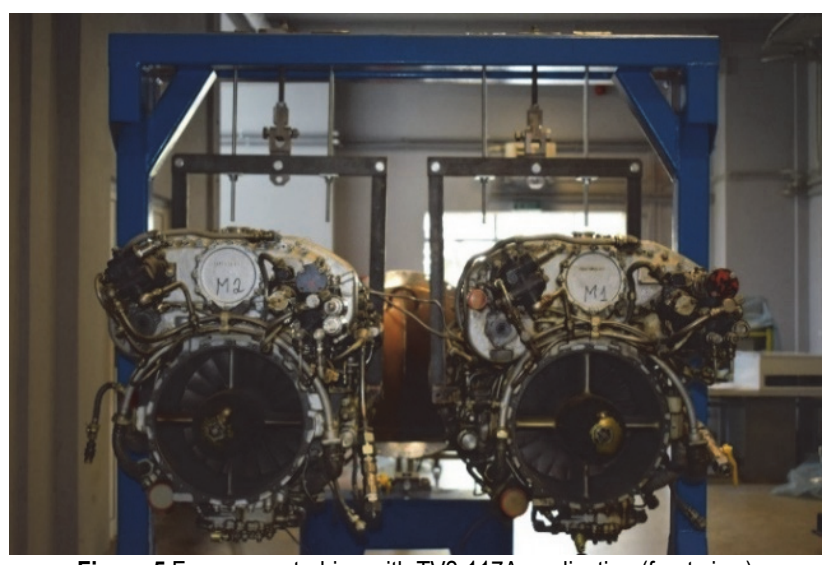

Figure 5 Free power turbine with TV2-117A application (front view)

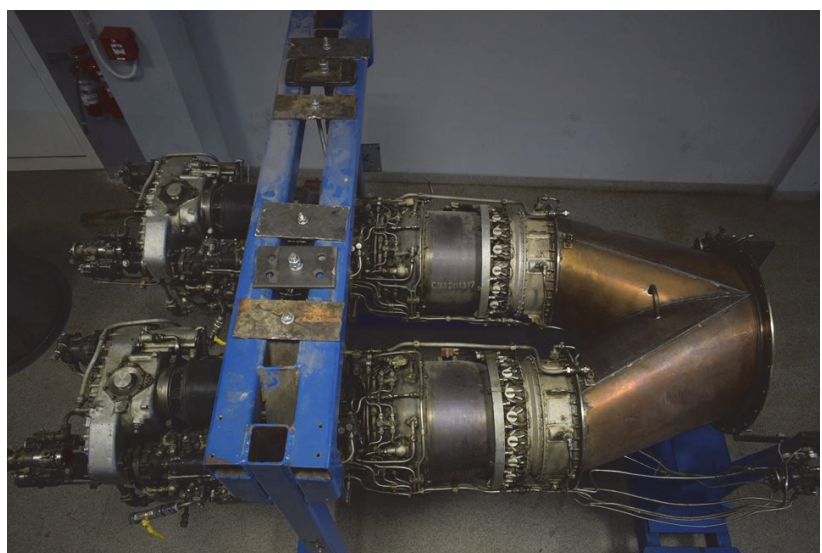

Figure 6 Free power turbine with TV2-117A application (top view)

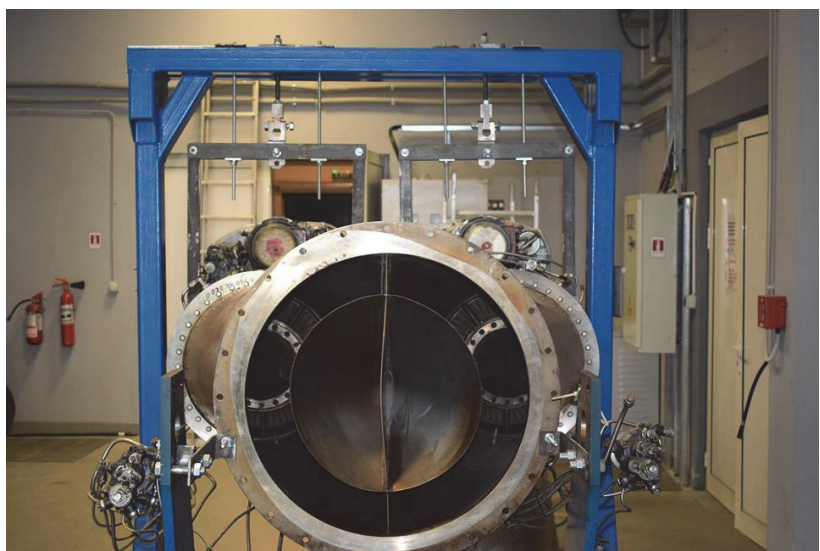

Figure 7 Free power turbine with TV2-117A application (rear view)

\section{ENGINES CONTROL AND OPERATIONAL MODE}

On helicopter configuration [15], the speed of free power turbine is controlled by a speed regulator. The free power turbine speed regulator is mechanically connected through a gear with the free turbine shaft and has the role to maintain constant the free power turbine speed, by fuel control, in connection with the engine main fuel pump. By removing the free power assembly module from the engine, the controller of the speed of free power turbine is also removed. So, in this case, an engine with a free power turbine without a turbine speed regulator is obtained

The free turbine is connected to the test bench by a shaft to a gear and through the gear to the dynamometer. The dynamometer [16] has the role to control the turbine speed and determine the produced shaft power. In the testing configuration, for this particular application, the 
speed of free turbine is controlled by the dynamometer operation mode, so the free power turbine is not controlled by the engine and is controlled by the dynamometer using the speed operation mode. The turbine speed is working as it is set from the dynamometer; in this case the dynamometer is like a speed regulator of the turbine. The dynamometer sets the running turbine speed and the engine must control the metered fuel to obtain the power at demanded speed. This configuration is seen in the Fig. 8.

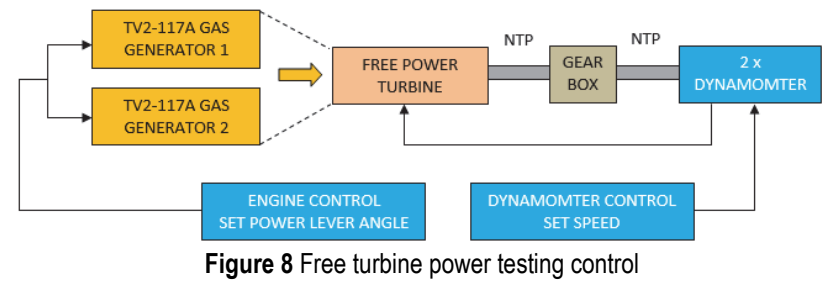

To test the free turbine, the engine must be started and must be in the idle mode, with the dynamometer set at starting turbine speed. In the starting phase, the dynamometer sets the speed, and the engines in the idle mode must obtain it. The dynamometer has the capability to start with different speeds of the free turbine and the engines must achieve the idle mode. If lower speed is demanded, the engine will start with a higher load on free turbine, or if higher speed is demanded, the engine will start with a lower load on free power turbine.

At rated power the free turbine is designed to work with $15000 \mathrm{rpm}$ speed and to produce $\approx 2600 \mathrm{~kW}$ power, using $\approx 16 \mathrm{~kg} / \mathrm{s}$ gas flow. At the idle mode the engines develop a gas flow at an entry turbine temperature and by gases expansion a difference of enthalpy results which is the specific actual work $l_{\mathrm{TS}}$ [17], where $\mathrm{h}_{3 \mathrm{~s}}$ and $\mathrm{h}_{4 \mathrm{~s}}$ is inlet enthalpy and outlet enthalpy of the free turbine.

$$
l_{\mathrm{TS}}=h_{3 \mathrm{~S}}-h_{4 \mathrm{~S}} \quad \mathrm{~J} /(\mathrm{kg} \cdot \mathrm{K})
$$

The power of turbine $\mathrm{P}$ can be evaluated by the specific work $l_{\mathrm{TS}}$ and gas flow $g f$ [17], or by torque $T_{\mathrm{q}}$ and demanded speed NTS.

$$
P=g f \cdot l_{\mathrm{TS}}=T_{\mathrm{q}} \cdot \frac{\pi \cdot N T S}{30} \mathrm{~kW}
$$

Because the total gas flow obtained from both engines is maximum $15 \mathrm{~kg} / \mathrm{s}$, the performance of the free turbine will be lower at various operating modes.

To test the turbine, it is necessary to control the engine and to control the free turbine speed. The simple procedure of free turbine testing is to set the turbine speed at $\approx 50 \%$, put the engine power lever into the $100 \%$ and then increase the free turbine speed by setting the speed value from $50 \%$ to $100 \%$ with a variation of maximum $10 \%$. In this present case, at starting phase, the engine starts with $7000 \mathrm{rpm} \approx$ $46.50 \%$ turbine speed. At every demanded turbine speed, it results with different power and torque values, until it gets the maximum allowable values.

\section{ENGINE OPERATING SEQUENCE}

To start the engines [18], the test bench holds an operating system which consists of acquisition and a control system with a programmable controller capable to execute the starting phase and to command the throttle to get operating modes above idle. To achieve the starting or testing, there are established the main parameters and main commands that will be instrumented to monitor the engine and the turbine running.

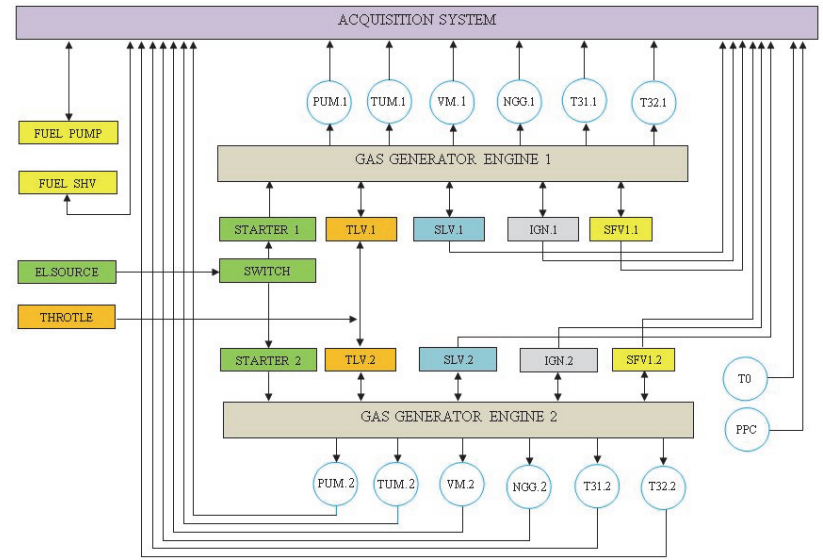

Figure 9 TV2-117A Instrumentations and acquisition system

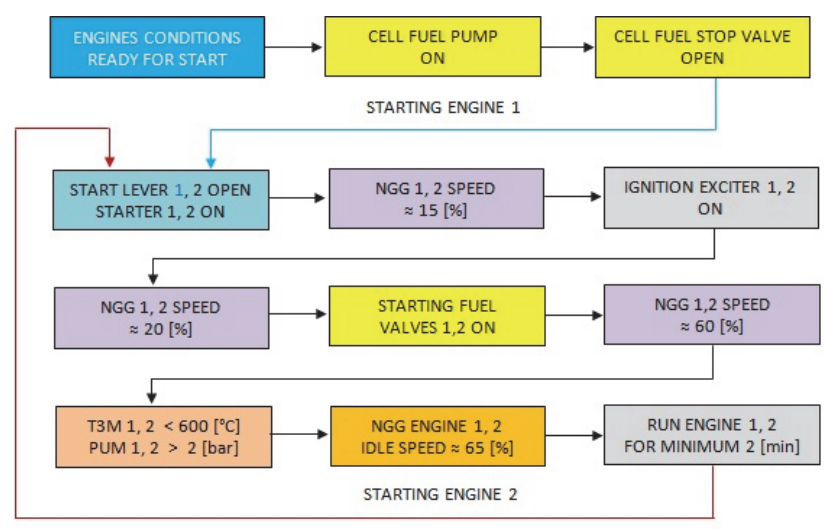

Figure 10 Engine starting phase TV2-117A to run the free turbine

For TV2-117A gas generator, it is established a standard instrumentation [19], Fig. 9, formed of main parameters as gas generator shaft speed $\mathrm{NGG}$, inlet turbine temperature T3M, oil pressure PUM, outlet oil temperature TUM, vibrations VM, free power turbine shaft speed NTP, inlet fuel pressure PPC. The engine main commands are switch power, starter, ignition, starting fuel valves SFV, start lever SLV, throttle lever TLV and external commands as fuel pump and a fuel shut off valve SHV.

For execution of the engine starting a general diagram is presented with the logic starting phase of the operating system on the test bench. In this case, only the engine run mode is shown. The engine run starting procedure contains the steps of the starting sequence.

Fig. 10 involves commands, confirmations and conditions that participate to the starting phase.

So thelogical starting sequence of engine run begins with a starting condition of a series of parameters which confirm that the engine is ready for starting [19].

To execute a hot starting or an engine run, it begins with following these global steps: turn on the fuel pump 
and if the fuel pressure increases above the minimum value then open the fuel shut of valve. Put the start lever into the idle position and turn on the starter. The starter increases the engine core speed, at $\approx 15 \%$ energises the ignition and at $20 \%$ it opens the starting fuel valves, to allow the fuel to enter into the engine fuel system and to be ignited in the combustion chamber. After the light-off, the engine is accelerating until $60 \%$ and must perform an oil pressure PUM higher than 2 bar, and the inlet turbine temperature must be lower than $600{ }^{\circ} \mathrm{C}$ and turn off the starter, ignition and starting fuel valves and then the engine will go out of idle mode. After the engine 1 is started, after minimum 2 minutes of operating the engine 2 starts in the same starting sequence.

For the starting examinations an interface display was made, Fig. 11, to monitor in real time the engine parameters, confirmations and commands, to be viewed by the engine operator. In the figure below, the TV2-117A engines and free power turbine monitoring display of an engine run starting is presented.

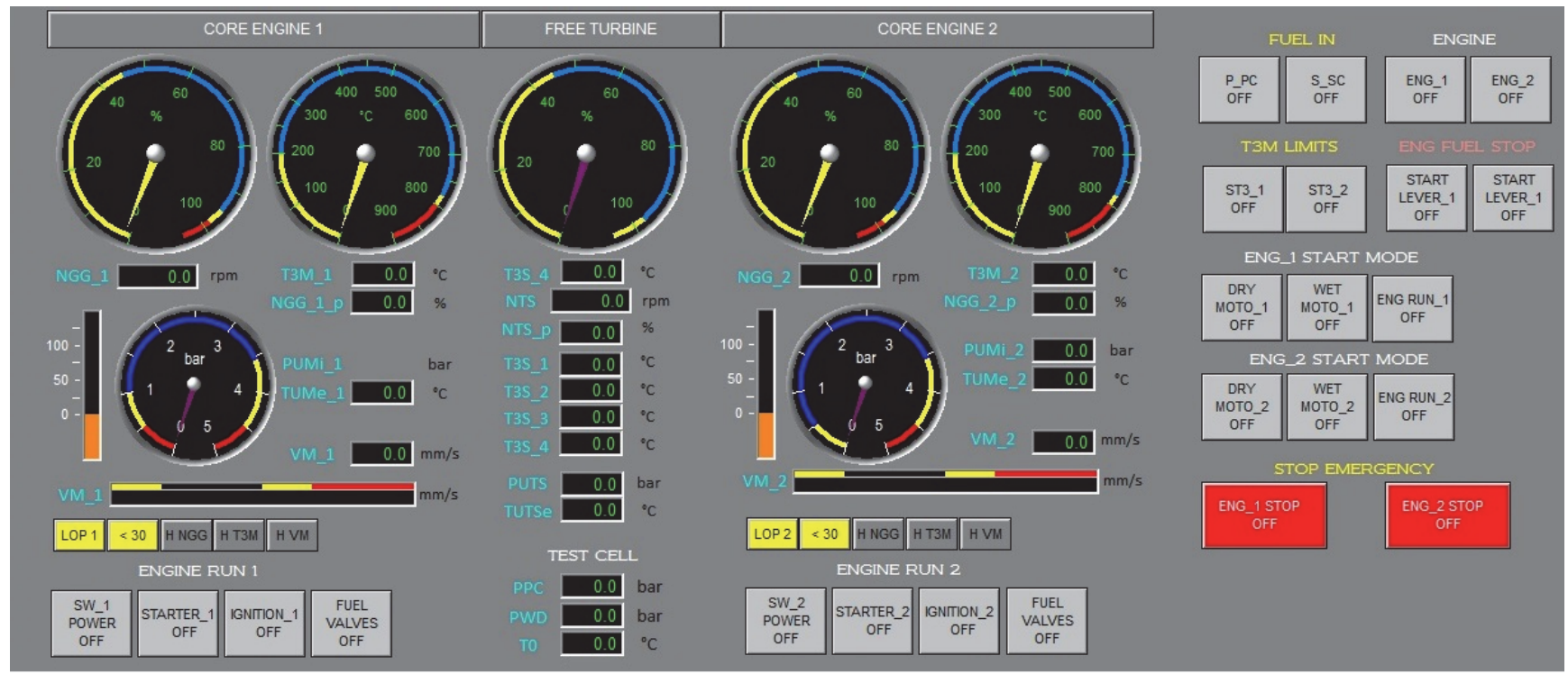

Figure 11 Engines and free power turbine monitoring interface

To monitor the parameters of the TV2-117A turboshaft and free turbine, a series of sensors and transducers was mounted on the engine and on the free turbine, presented in the figure below, Fig. 12.

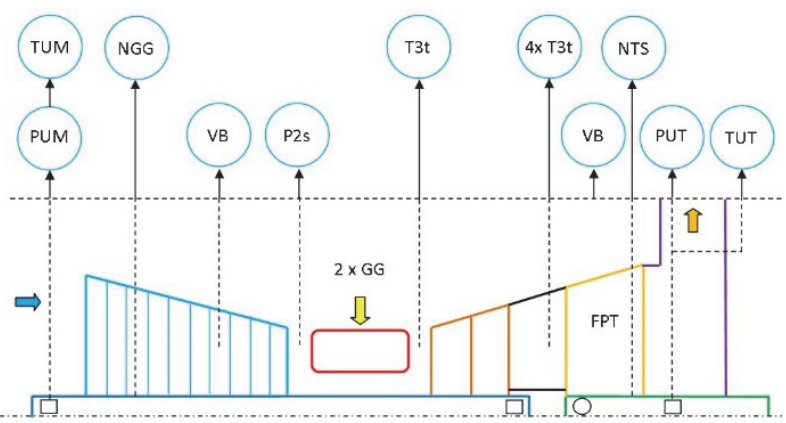

Figure 12 Sensors and measuring devices for TV2-117A turboshaft engine

For measuring the engine speed NGG, free turbine speed NTP, outlet engine oil temperature TUM, fuel flow DC, vibrations VBM, it is used an inductive speed transducer, pressure transducers, Pt100 sensor, a fuel flow meter and accelerometers. For measuring of inlet turbine temperature $\mathrm{T} 3 \mathrm{M}$, the engine is equipped with thermocouples.

\section{RESULTS}

According to the operation mode, the free turbine can be controlled from the $7000 \mathrm{rpm}$ idle speed to the 15000 $\mathrm{rpm}$ nominal or rated mode speed. In this case, the free turbine has been tested only at idle mode and it is analysed how the engine responds at idle demanded speed of the free turbine.

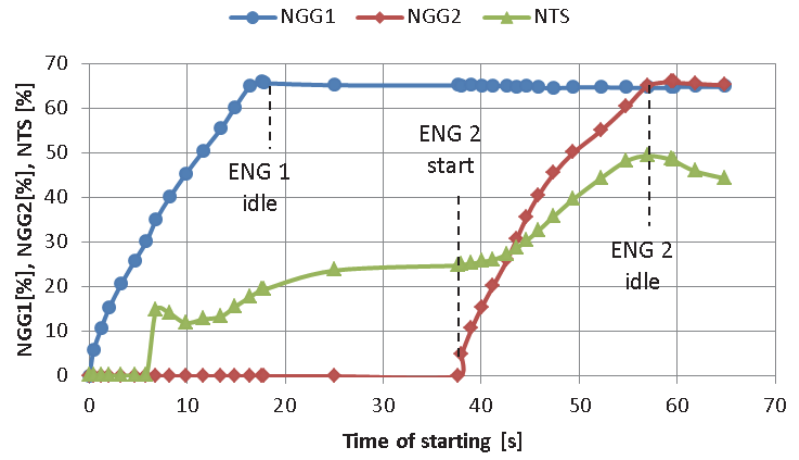

Figure 13 Engine speed variation with free turbine starting time

Following the test of free turbine run by two modified TV2-117A turboshaft engines, on the test bench, a series of variation curves between engine main parameters and turbine main parameters was obtained.

In the first diagram, Fig. 13, it is presented the variation of gas generator speeds and free turbine speed with the starting time. It can be noted that the free turbine speed variation depends on which engine is working and at what values of core speed are.

In the second diagram, Fig. 14, it is presented the variation of free turbine power, torque and speed in time of starting. The curves have an irregular increase and also depend on the core engines operational modes.

From the curve variation of Fig. 14 it can be noted that when the first engine is on idle, the free turbine speed 
achieves $\approx 3750 \mathrm{rpm} \approx 25 \%$. After the second engine is started and got to idle, the free turbine speed increases and exceeds the limit of $7000 \mathrm{rpm}$. When the free turbine speed achieves $7500 \mathrm{rpm}$, the dynamometer controls the speed and reduces it at the set value of $7000 \mathrm{rpm}$. At this speed, the engine starts and gets normally to idle, which involves that the set free turbine speed does not block the gas flows from engine and does not make a backpressure such that the engine does not start or gets to the idle. The free turbine speed has an irregular increase at $\approx 20 \%$ until the engine one gets on idle core speed of $65 \%$ and a small increasing to $\approx 24 \%$ in time of engine one idle mode.

When the engine two is started the free turbine speed has an accentuated increase, exceeds the set speed of $46 \%$, achieves $50 \%$, and the dynamometer controls and reduces the speed at $46 \% \approx 7000 \mathrm{rpm}$.

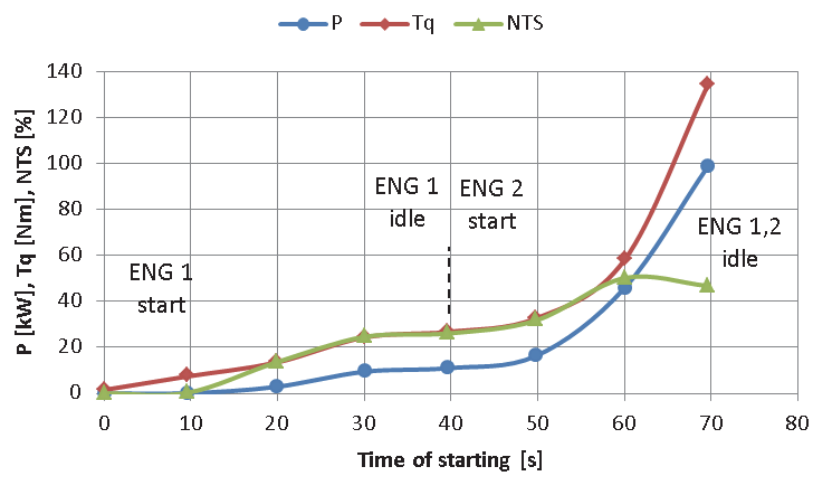

Figure 14 Free turbine performance variation with starting time

In the third diagram, Fig. 15, it is presented the variation of gas generator inlet turbine temperatures $\mathrm{T} 3 \mathrm{M} 1$, 2 and free turbine inlet T3S, temperature with the free turbine speed NTS. Also, the variation of the curves depends on how the engines started and the idle set value of the free turbine speed.

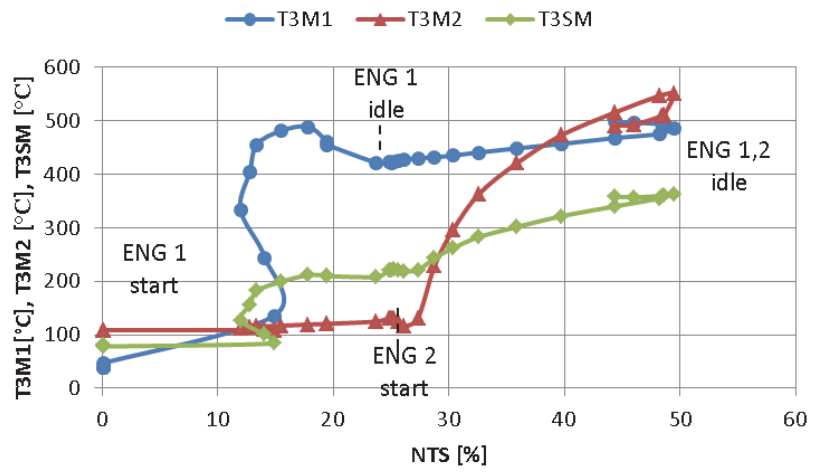

Figure 15 Inlet turbine temperatures variation with free turbine speed

From the curve variation of Fig. 15 it can be noted that with the first engine on idle and with the free turbine speed at $\approx 25 \%$, the turbine develops $11 \mathrm{~kW}$ power at $26.8 \mathrm{~N} \cdot \mathrm{m}$ torque. When both engines are on idle, the turbine develops $98.82 \mathrm{~kW}$ at $134.4 \mathrm{~N} \cdot \mathrm{m}$ torque. So with one engine, the free turbine develops $56 \%$ from the idle speed and $\approx 11 \%$ power from the idle power. In these conditions, it results on idle, at $46 \%$ speed, the free turbine develops power $\approx 4 \%$ from rated power. It is mentioned that before the start of the turbine test, the engines were started one by one to check if they normally get on idle that is why on the diagram, the second engine starts with the inlet turbine temperature at $\approx$
$100{ }^{\circ} \mathrm{C}$. When the first engine is on starting, the inlet turbine temperature T3M1 achieves a maximum of $\approx 490$ ${ }^{\circ} \mathrm{C}$ and when it gets on idle mode, the temperature decreases at $\approx 422{ }^{\circ} \mathrm{C}$. For this temperature T3M1 it results an inlet free turbine temperature at $\approx 220^{\circ} \mathrm{C}$. At this time, the gas flow from the first engine enters into the free turbine and produces an increasing of the inlet temperature turbine T3M2 of the second engine. It is possible that, at entry of the free turbine, a part of the heat from the first engine gas flows at the outlet number one of the exhaust module, to be transferred to the second outlet of the exhaust module and it is taken in consideration a possible reverse of a part of the gas flow, producing the increase of the inlet temperature of the second engine. So in this case the inlet turbine temperature $\mathrm{T} 3 \mathrm{M} 2$ achieved $\approx 135{ }^{\circ} \mathrm{C}$. After the first engine is on idle, the second engine starts. During the second engine starting, until the $\approx 25 \%$ core speed NGG2, the inlet turbine temperature $\mathrm{T} 3 \mathrm{M} 2$ decreases at $\approx 125^{\circ} \mathrm{C}$ and after the engine light-off, goes to $\approx 296{ }^{\circ} \mathrm{C}$, during acceleration until it gets on idle, it results a maximum value at $\approx 550{ }^{\circ} \mathrm{C}$, and when it gets on idle, the inlet turbine temperature decreases at $\approx 490{ }^{\circ} \mathrm{C}$. At the same time, the gas flow on the idle of the second engine has an influence in increasing the inlet turbine temperature of the first engine $\mathrm{T} 3 \mathrm{M} 1$. The inlet turbine temperature $\mathrm{T} 3 \mathrm{M} 1$ increases with $\approx 70{ }^{\circ} \mathrm{C}$ that means an increase of $\approx 18 \%$. That is explained by forming the backpressure in front of the free turbine translated to the exit of the core turbine, depending on the speed of the free turbine, set from the dynamometer. When both the engines are on idle mode, the inlet turbine temperature of the core engine is on the same value of $\approx 490{ }^{\circ} \mathrm{C}$. Regarding the variation of inlet free turbine temperature it is observed that the temperature has a continuous increase until the first engine gets on idle and achieves $\approx 220{ }^{\circ} \mathrm{C}$. After the engine two is started, the free inlet turbine temperature has a continuous increase until it achieves a maximum of $\approx 365^{\circ} \mathrm{C}$ and the set free turbine idle speed is established at $\approx 350^{\circ} \mathrm{C}$.

\section{CONCLUSSIONS}

The paper examines a particular test of a free turbine performed by modification of two engines, which are installed on the test bench in connection with the free turbine and dynamometer, to be started and to be controlled for the operation, using an automatic system. Also, the free turbine is controlled by the dynamometer using the constant speed setting mode of operation. During the engines starting and getting on idle, the dynamometer has the control of the free turbine idle speed and maintains constant speed, set at $7000 \mathrm{rpm}$.

In conclusion, according to the technical solution of the exhaust module which collects the gas flow from each engine and directs the gas flow into one turbine, it is observed that the engine has influence on the inlet turbine temperature of the core engines. That is why it is important at which value the speed of free turbine is established to perform the starting and to get the idle free turbine on the demanded speed. If the set starting free turbine speed is too low, the engine could be blocked during the starting and it makes impossible for the engine to be started, and in this case to test the turbine is needed a different procedure of getting the modes higher than the idle mode. If the set 
starting free turbine speed is higher, then it has the advantage to perform more easily the starting of the engines and it has a lower influence in increasing the inlet turbine of each engine.

\section{REFERENCES}

[1] Bhargava, R., Bianchi, M., De Pascale, A., \& Montenegro, G. (2007). Gas Turbine Based Power Cycles-A State-of-theArt Review. Challenges of Power Engineering and Environment, 309-319. https://doi.org/10.1007/978-3-540-76694-0_56

[2] Bhargava, R. K. (2006). Global energy market-Past, present, and future. ASME Paper No. GT2006-91322, https://doi.org/10.1115/GT2006-91322

[3] See https://www.integratechnical.com/wp-content/uploads/ 2018/01/Aeroderivative-or-Industrial-Gas-TurbinesArticle.pdf

[4] See https://www.power-eng.com/2012/01/01/large-aeroderivative-gas-turbines-for-power-generation/\#gref

[5] See https://www.rolls-royce.com/products-and-services/ power-systems.aspx\#/mtu

[6] See https://www.ge.com/power/gas/gas-turbines

[7] Seehttps://new.siemens.com/global/en/products/energy /power-generation/gas-turbines.html

[8] See https://turbinetechnics.com/pw-ft8-gg8

[9] See https://www.mhi.com/products/industry/industry_ engine_power_plant.html

[10] See https://www.mtu.de/engines/industrial-gas-turbines/

[11] Seehttps://turbomachinery.man-es.com/products/gasturbines

[12] See https://www.poweronline.com/doc/flowtronex-prattwhitney-sign-gas-turbine-pac-0001

[13] See http://www.motorsich.com/ukr/products/land/seriynaya /ge/ai-20D/

[14] See http://www.klimov.ru/en/

[15] TV2-117A Base Maintenance and Training Manual, Bucharest, 1973

[16] Instruction Manual, Operator's Hydraulic Dynamometer Type HS2600, Issue 1, 2007

[17] Meherven, B. (2001). Gas Turbine Engine Handbook - $2^{\text {nd }}$ ed., Chapter 9, British Library.

[18] Cican, G., Stanciu, V., Silvestru, V., \& Catana, R. M. (2016). Fundamentals of Gas Turbine Engine Starting. Processes and Experiments, Printech, Bucharest.

[19] Catana, R. M., Cican, G., \& Dediu, G. (2017). Gas Turbine Engine Starting Applicated on TV2-117 Turboshaft. Engineering, Technology \& Applied Science Research, 7(5), 2005-2009. https://doi.org/10.48084/etasr.1315

[20] See https://szextant.blogspot.com

\section{Contact information:}

Razvan Marius CATANA, PhD Engineer, Gas Turbines Test Bench

(Corresponding author)

National Research and Development Institute for Gas Turbines COMOTI,

61129 Bucharest, Romania, Boulevard luliu Maniu, No. 220D

E-mail: razvan.catana@comoti.ro

Gabriel DEDIU, PhD Student Engineer, Gas Turbines Test Bench

National Research and Development Institute for Gas Turbines COMOTI,

61129 Bucharest, Romania, Boulevard luliu Maniu, No. 220D

E-mail: gabriel.dediu@comoti.ro

Cornel Mihai TARABIC, Engineer, Gas Turbines Test Bench

National Research and Development Institute for Gas Turbines COMOTI,

61129 Bucharest, Romania, Boulevard Iuliu Maniu, No. 220D

E-mail: cornel.tarabic@comoti.ro 